\title{
O poeta da experimentação: Augusto de Campos e a crise do verso
}

Arlindo Rebechi Junior

Docente do Departamento de Ciências Humanas da Faculdade de Arquitetura, Artes e Comunicação (FAAC) da Universidade Estadual Paulista (Unesp). Doutor em Literatura Brasileira pela Faculdade de Filosofia, Letras e Ciências Humanas da Universidade de São Paulo. E-mail: arlindo@faac.unesp.br

\section{TRAJETÓRIA INTELECTUAL INICIAL}

Nascido em 1931, em São Paulo, Augusto de Campos vive uma vida entre livros. Sua trajetória intelectual esteve sempre envolta à poesia, embora não exclusivamente a ela. Exímio tradutor, junto com seu irmão, Haroldo de Campos, foram responsáveis por trazer, ao público brasileiro, grandes autores de diferentes épocas da literatura mundial; cabe a lembrança de alguns nomes: Ezra Pound, James Joyce, Étienne Mallarmé, e. e. cummings, entre tantos outros. Por meio de uma crítica cultural bastante original, que mobilizou pesquisa e leitura analítica invulgares, ele pôde gravitar em torno de autores e épocas, gêneros e expressões artísticas de diferentes linhagens, realizando um arco investigativo que passou pela música de vanguarda, pela música popular brasileira e por autores (prosadores, ensaístas ou poetas), brasileiros ou não. Como forma de demonstrar a originalidade de suas pesquisas, com coletas de material literário disperso, é relevante lembrar que os irmãos Campos foram responsáveis por fazer circular obras de autores de nossa literatura que já beiravam um certo esquecimento: é o caso de Sousândrade e de Pedro Kilkerry, poetas nascidos no século XIX, de Oswald de Andrade e Pagu, ambos modernistas.

No Brasil, a geração de 1945 de poetas, no pós-guerra, embora sem um programa delineado por um manifesto, representou um movimento poético que promoveu a revisão de uma poesia de vanguarda ligada ao nosso modernismo, reavivando formas poéticas tradicionais e trazendo um tipo de valorização em torno do acabamento poético e da unidade harmônica na poesia. Tanto a Revista 
Brasileira de Poesia como os conhecidos Clubes de Poesia foram os veículos desse movimento poético para a produção crítica e a difusão de seus poetas. Nessa revista, em 1949, Augusto publica seus primeiros poemas.

A estreia em livro se deve à obra O rei menos o reino, de 1951. Do volume, podemos extrair versos como "Onde a Angústia roendo um não de pedra”, de cuja dicção já se pode antever um rigor formal bastante acentuado que se liga a uma tensão existencial, oferecendo aos seus leitores contemporâneos as primeiras marcas de um distanciamento e de uma distinção ao que era peculiar à poética da geração de 1945. Desde então, seria uma distinção que se ampliaria gradativamente na composição de seus poemas, sempre em sentido oposto à lógica discursiva mais comum e presente em boa parte dos poemas daquela época.

\section{O GRUPO NOIGANDRES E A POESIA CONCRETA NO BRASIL}

Marco de uma ruptura do poeta e de seu grupo com a poesia dos anos 1950 está a iniciativa da criação da revista Noigandres, em São Paulo, no ano de 1952. Fundada por Augusto de Campos, seu irmão Haroldo de Campos e pelo também novato poeta Décio Pignatari, esse veículo se tornaria o porta-voz de seu movimento e promoveria a agenda programática da poesia concreta brasileira. Ligado a uma prática de vanguarda, numa referência direta aos postulados de frações significativas de modernistas de início do século XX, a poesia concreta brasileira se ligaria, em nível internacional, a outros grupos, ampliando o campo de irradiação de Augusto e seus companheiros de movimento.

Eles empenharam-se numa radicalização que explorava a poesia em outras chaves de leitura e permitia desconstruir traços distintivos, até então, do texto poético. Não parece ser coincidência que uma de suas primeiras estratégias foi fazer com que suas poesias frequentassem espaços pouco usuais; refiro-me aos museus, bienais de arte e galerias.

Entre as estratégias do grupo Noigandres, estava a de formalizar um cânone de apoio com seus precursores. Nessa lista, o poeta francês Mallarmé foi figura de destaque. A publicação do poema "Un coup de dés" ("Um lance de dados”), em 1897, ia ao encontro de uma ideia central na poética de Augusto e seu grupo: construir um poema não era necessariamente compor um verso. Estava, por assim dizer, instituída a crise do verso e a ela se ligava também um novo processo de organização poética, a partir de alguns pontos divulgados no prefácio do poema mais famoso desse autor francês. Dessa maneira, Mallarmé estipulava os seguintes pontos definidores da nova prática, cujas orientações tornariam uma das bases constitutivas das linhas de atuação de Augusto de Campos e seus companheiros de movimento: a utilização mais funcional dos

1 MALLARMÉ, S. Um lance de dados. In: CAMPOS, Augusto; CAMPOS, Haroldo; PIGNATARI, Décio. Mallarmé. São Paulo: Perspectiva, 2006, p. 151. recursos gráficos e tipográficos; as páginas e o papel como integrantes da linguagem do poema, dizendo que "o papel intervém cada vez que uma imagem, por si mesma, cessa ou recede, aceitando a sucessão de outras”; o poema, tal como a música, se organiza por uma hierarquia de motivos. 
Recuperada dentro de uma tradição estabelecida pelos movimentos modernos mais radicais e somadas a outras ideias e precursores, as ideias de Mallarmé são aqui aclimatadas e estabelecem o fio que conduzirá o grupo dos poetas concretos. O próprio Augusto de Campos, em artigo intitulado "Poesia, Estrutura" e publicado, originalmente, no Diário de São Paulo, em 20 de março de 1955, diz o seguinte sobre a relevância do poeta francês como inventor de uma nova forma poética:

Mallarmé é o inventor de um processo de organização poética cuja significação para a arte da palavra se nos afigura comparável, esteticamente, ao valor musical da "série", descoberta por Schoenberg, purificada por Webern, e, através da filtração deste, legada aos jovens compositores eletrônicos, a presidir os universos sonoros de um Boulez ou um Stockhausen.

\section{A CRISE DO VERSO: A POESIA DE VISUALIDADES EM AUGUSTO DE CAMPOS}

Os resultados dessas primeiras incursões, já sob esse critério em termos de vanguardismo estético e literário, já podem ser notados nos poemas publicados de maneira dispersa na revista Noigandres, de onde ressoavam os poemas iniciais do grupo de jovens poetas concretos. É emblemático do período o poema de Augusto "lygia fingers", reunido dentro da série Poetamenos, datados de 1953, com aparição na revista em 1955:

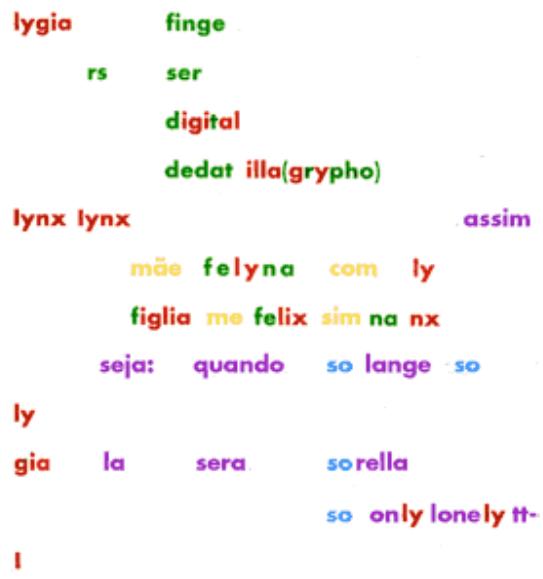

Esse poema compõe a fase inicial da produção do poeta paulista. Havia, sem dúvida, como se pode notar visualmente, o abandono do verso e a ocupação do 
espaço por um modo não tradicional. Dali em diante, o espaço passaria a ser um agente que estrutura os significados e torna a poesia visualmente presente em seu suporte. Inspirado na música de Webern, as palavras assumem no poema melodias de uma cor a outra, como se as melodias de uma música estivessem sendo deslocadas de um instrumento a outro. Isso explica a necessidade de representação gráfica por cores em muitos dos poemas dessa fase inicial.

O verso mais livre no espaço gráfico da página significava para Augusto o rompimento com a centralização da leitura por um único eixo. O leitor, com o projeto da poesia concreta, poderia aplicar sua leitura em múltiplas direções, e o seu olhar poderia acompanhar de baixo para cima, de cima para baixo, da direita para a esquerda e da esquerda para a direita, ampliando as possibilidades significativas de um poema. Vejamos um exemplo posterior à série de Poetamenos; trata-se do poema "Tensão", que desenvolve um pouco mais o modo de explorar o espaço gráfico da página:

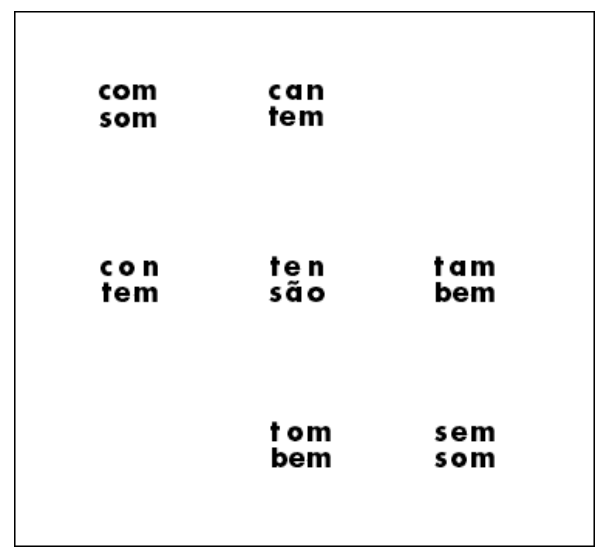

“Tensão" é um poema de Augusto de Campos com data de 1956. Construído a partir de um trabalho primoroso com o som, o poema estabelece um jogo geométrico e simétrico que atravessa o espaço visual da página. Augusto de Campos cria pelo poema a própria negação do verso tradicional (como unidade rítmico-formal) e estabelece um tipo de ruptura com a sintaxe verbal lógica e discursiva. Em substituição a esse modelo tradicional, o percurso dessa nova forma dependeu, segundo essa concepção concretista, da espacialidade e proximidade dos elementos que resultam do poema. Não há uma única direção na leitura; por exemplo, de ten-são (centralizado geometricamente na página), que dá o título do poema, podemos vislumbrar algumas matrizes dispostas em oposição semântica e espacial a partir de um corte de leitura diagonal — caso de com-som e sem-som: silêncio e som formulam uma tensão entre significados, por assim dizer, opostos.

Uma radicalização do poeta se dá, a partir dos anos 1960, na medida em que sua poesia começa a acrescentar elementos até então inéditos, formados 
por signos estritamente não verbais. Até aquele momento, os poemas concretos de Augusto de Campos, embora fizessem um uso espacial da palavra, jamais abandonaram o uso do alfabeto como elemento central. A experiência dos Popcretos está circunscrita exatamente ao uso de novas unidades de significação que se projetam além do domínio do nosso alfabeto e a um diálogo mais aproximativo com os meios de comunicação de massa. Saindo dos livros e ganhando novos espaços de difusão, os poemas dessa série foram construídos em grandes painéis para uma exposição na Galeria Atrium, em 1964, na cidade de São Paulo. Popcretos foram compostos a partir de uma matriz à época rejeitada pelo campo literário: a composição de imagens no poema era feita e adquirida nos recortes de jornais e revistas, em experiência que traz em diálogo os trabalhos dos anos 1920 de Kurt Schwitters². Cabe um exemplo dessa série; o poema em questão é denominado "Psiu!":

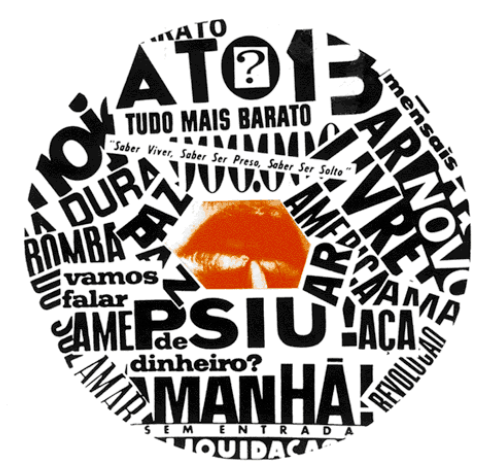

Também dos anos 1960 vem sua poesia de maior aproximação, senão adesão, à crítica social. Ou como o próprio Augusto disse: "o salto participante". Além de "Psiu!", é emblemático do período outros dois poemas: "Luxo", de 1965, e "Greve", de 1961, cuja dicção do poeta ligará um tipo de invenção visual a uma forma de crítica social e poética. Eis, respectivamente, esses dois poemas:

\begin{tabular}{|c|c|c|c|c|}
\hline XEXO & 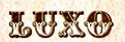 & 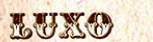 & 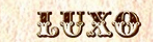 & 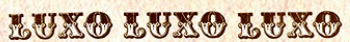 \\
\hline 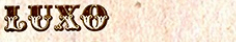 & MUXXO & 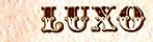 & 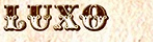 & MUXS \\
\hline EESA & 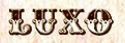 & 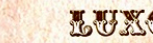 & GSBO & WEX \\
\hline 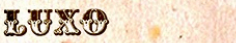 & MUSO & 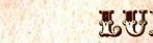 & 8080 & [OWXS \\
\hline 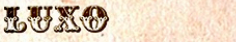 & 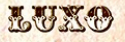 & & & XEX \\
\hline MUSOSO & 20350 & EU & 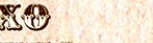 & 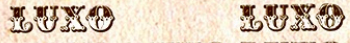 \\
\hline WUXE & MUXX3) & 恶焉X & MXOS & 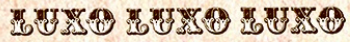 \\
\hline EUXX & 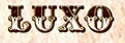 & 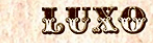 & & 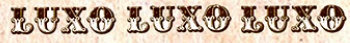 \\
\hline EXXE & 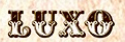 & 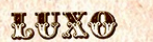 & 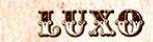 & 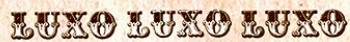 \\
\hline
\end{tabular}

2 Cf. AGUILAR, Gonzalo. Poesia concreta brasileira. São Paulo: Edusp, 2005, p. 108. 
comunicação \& educação • Ano XX • número 2 • jul/dez 2015

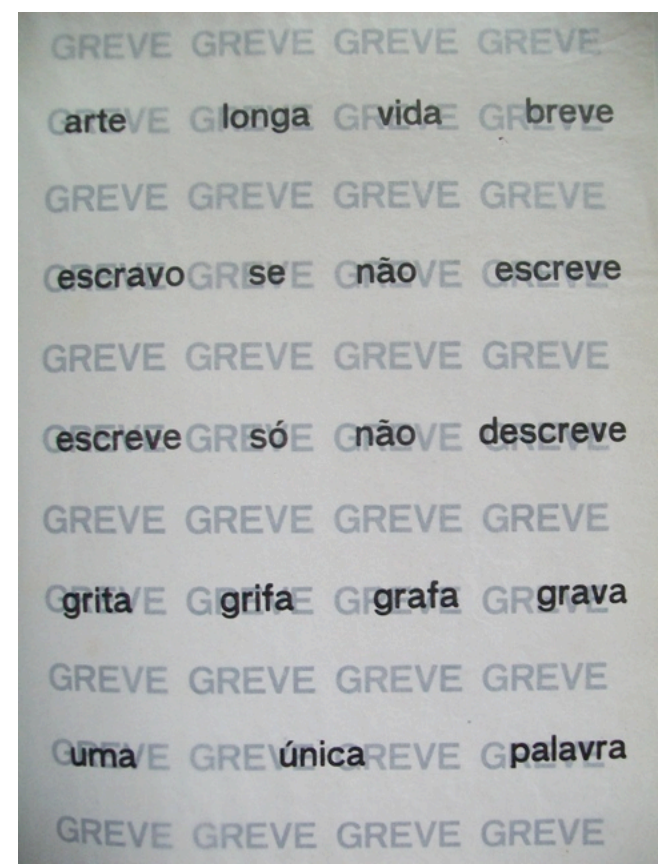

Demarcado, sem dúvida, pelo uso da tipografia de forte inspiração kitsch, trazida do universo das propagandas de imóveis de alto luxo da época, o poema "Luxo" traz em si uma inscrição macrovisual da palavra "lixo" construída pela aglutinação de várias palavras "luxo", cujo efeito penetrante está mediado pela formulação paródica entre dois polos opostos: do luxo se vislumbra o lixo e vice-versa.

Em "Greve", não se deve perder no horizonte o suporte material originalmente presente no poema: a folha transparente, em papel vegetal, com a inscrição dos versos, assume uma posição acima da folha branca que apresenta repetições da palavra "greve". O efeito é de uma dupla voz que se alterna e se dialetiza no poema. Ali, está o trabalho do poeta com os jogos de significação em camadas sobrepostas: seja sob o aspecto espacial e visual, com as palavras que se justapõem à palavra "greve", repetida 44 vezes; seja pelas leituras possíveis do poema no jogo de interação que se repete, continuamente, com os sentidos de greve.

\section{OUTRAS PRODUÇÕES IMPORTANTES DE AUGUSTO DE CAMPOS, EM PERÍODO POSTERIOR}

A seguir apresentamos mais quatro poemas representativos do período entre o início dos anos 1970 e meados da década seguinte. De modo bastante sumário, convém dizer algumas palavras sobre essas quatro produções. "Viva Vaia" é um poema emblemático do período de produção de Augusto de Campos e é dedicado a Caetano Veloso. Bastante provocativo e totalmente alinhado à perspectiva concretista, pois, afinal, a "imagem e o texto fazem parte de um mesmo campo experimental, em que são investigadas suas possibilidades materiais" ${ }^{3}$ "Código" (1973) está circunscrito a uma escrita ideogramática do poeta. Formulado sob a forma do espiral, 
em que leitor/leitura sempre refazem o percurso de leitura, o poema coloca em evidência o centro das preocupações do poeta: a metamorfose poética que o jogo linguístico/visual permite em todas as suas dimensões. Não à toa, de um sentido a outro, é possível ler "dog”-"god”; "código"-“digo”, o que demonstra a força constitutiva da linguagem. Em "O pulsar" (1975), que enfeixa a série Stelegramas (1975-1978), mais uma vez, nota-se a grande ambição poética, a um só tempo, no campo visual e verbal de Augusto. É um poema construído pelo sistema de letras transferíveis Letraset, com o uso de um tipo de decalque tipográfico que também contemplava o desenho; no jogo de leitura, o leitor, entre outras coisas, é colocado a descobrir uma estrela que se transforma em "e" e a lua, em "o". Por fim, "Pós-tudo" é talvez o poema mais polêmico publicado por Augusto de Campo. Com sua aparição no ano de 1985 no suplemento "Folhetim", da Folha de S.Paulo, as reações a esse poema não demoraram a surgir. A resposta mais incisiva à pretensão do poema veio, nesse mesmo suplemento, do crítico literário Roberto Schwartz, que viu, na ambiguidade (ou indefinição!) trazida pelo poema uma espécie de tentativa de forjar um marco histórico e canônico em torno do movimento de poesia concreta, do qual Augusto de Campos foi um dos principais nomes.

"Viva Vaia" (1972)

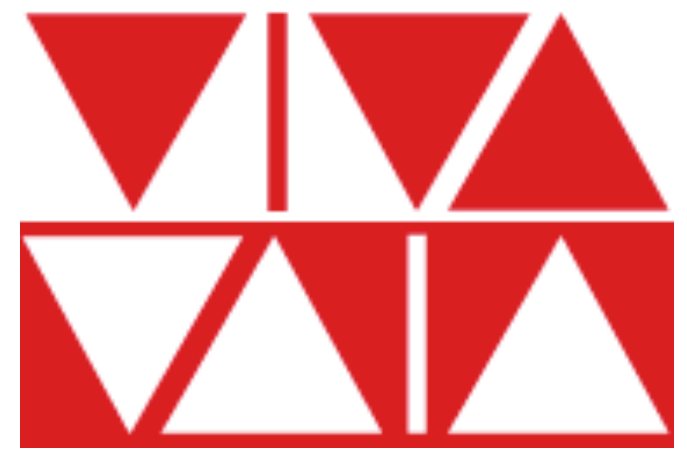

“Código" (1973)

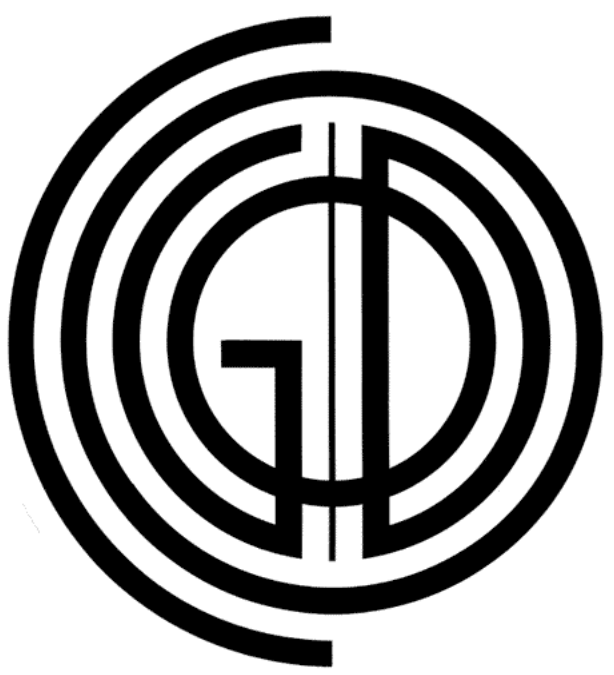


comunicação \& educação • Ano XX • número 2 • jul/dez 2015

“O pulsar” (1975)

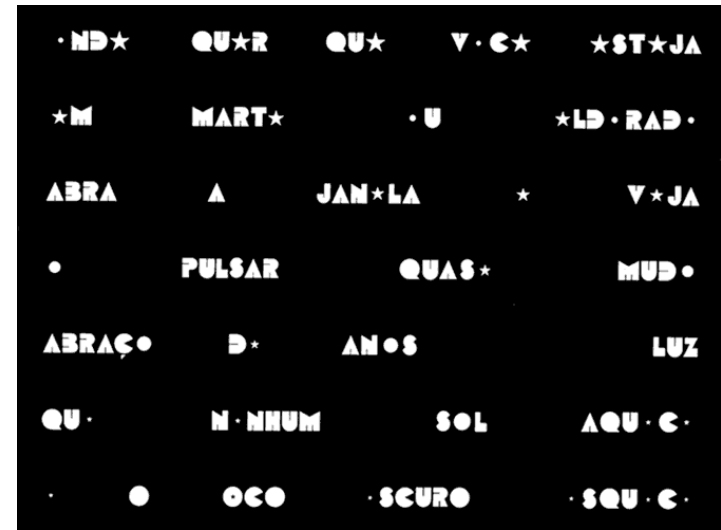

"Pós-tudo" (1984)

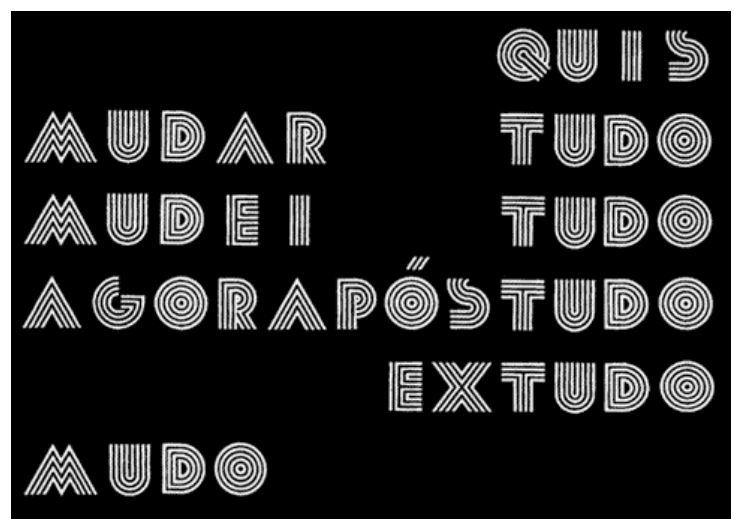

\section{REFERÊNCIAS}

AGUILAR, Gonzalo. Poesia concreta brasileira: as vanguardas na encruzilhada modernista. São Paulo: Edusp, 2005.

CAMPOS, Augusto de. O rei menos o reino. São Paulo: Edições Maldoror, 1951. . Poetamenos (1953). 2. ed. São Paulo: Edições Invenção, 1973.

.Viva Vaia (Poesia 1949-1979). São Paulo: Ateliê Editorial, 2000.

; CAMPOS, Haroldo; PIGNATARI, Décio. Teoria da poesia concreta. São Paulo: Ateliê Editorial, 2006.

GUIMARÃES, Júlio Castañon; SUSSEKIND, Flora (orgs.). Sobre Augusto de Campos. Rio de Janeiro: 7 Letras, 2004.

MALLARMÉ, S. Um lance de dados. In: CAMPOS, Augusto; CAMPOS, Haroldo; PIGNATARI, Décio. Mallarmé. São Paulo: Perspectiva, 2006.

SIMON, Iumna Maria; DANTAS, Vinícius. Poesia concreta. Coleção Literatura Comentada. São Paulo: Nova Cultural, 1982. 